\title{
Are the Elderly Averse to Technology?
}

\author{
Jonathan Jones ${ }^{1,}$ Peter Bednar ${ }^{2}$ \\ 1 University of Portsmouth, School of Computing, \\ Portsmouth, UK \\ jonathan.jones1@hotmail.com \\ 2 University of Portsmouth, School of Computing, \\ Portsmouth, UK \\ peter.bednareport.ac.uk
}

\begin{abstract}
In 2018, I interviewed seven people from the 'silent generation' to find out what they thought about information technology, whether they were averse to it, and why. Using this snap-shot image from Hornchurch Tapestry day care centre, this paper analyses the human activity system that frames how the elderly interact with the technology that surrounds them. It details what these interactions consist of, investigates how the participants view the purpose of the technology and explores how they 'feel' about their interactions with it. Ultimately, this paper challenges a societal assumption that elderly people are averse to information technology. The elderly use different technologies for different purposes and in different contexts. The Tapestry interviews highlight how critical family pressure was in determining how the elderly feel about information technology and their decisions to interact with it.
\end{abstract}

Keywords: Socio-Technical, Systems, Elderly, Averse, Information Technology, Information Systems

\section{$1 \quad$ Introduction}

It is a widespread societal view in the United Kingdom (UK) that the elderly are innately averse to technology. Just last year, The Guardian ran a story that exclaimed, "Older people can't cope with new technology - but nobody cares"[5]. This research was predicated on the view that such a societal assumption ignores how different people interact with different technologies in different ways. Moreover, Patilla-Góngora et al research found that 74.5\% of their elderly participants did not know the basic element of computer use [14].This research further shows that over $90 \%$ did not have the skills in databases, presentation creation, graph creation or web page creation [14]. To explore whether elderly people are averse to technology, I conducted semistructured interviews with residents from Hornchurch Tapestry day care centre. The interviews sought to uncover what technologies the participants interacted with, why they did so, and how they felt about these interactions. These interviews provide this paper with a snapshot insight into the various views that elderly people hold about technology and why they might use it. 
A participant's interactions with technology is characterised by purposeful action and they will interpret technology in different ways, as they interpret the world in different ways [4]. Peter Bednar states that a system is defined by interest [2]. As such, we ask what interest the elderly have towards 'information technology'.

As new information technology arrives, an elderly person may have to adapt to the new technology or at least be surrounded by a new technology. In this piece, we try to uncover what might affect an elderly person's will and ability to adapt to new technology. Eden Mumford states that there are values, attitudes and incentives for change and that some more than others may feel less threatened by change [13].

Without a boundary "we will have to take the whole planet into account, which of course we cannot do" [16] So, when this paper talks about technology, it is of course referring to information technology. As such, we do not ask participants to talk about the steam engine, cars, or even electric toothbrushes. Instead we ask how participants interact with information processing technology like tablets, personal computers, and smart phones. By conducting semi-structured interviews, we enabled participants to reflect upon their responses and return to them if needs be. This conversational approach led the interviews to explore unforeseen ideas and themes. The interviews were semi structured for a mix of reasons, firstly, I wanted more of a conversation style, and from this conversation style hopefully we could a high level of complexity around and outside the subject area. Secondly, as the interviews were 'face-to-face' I wanted to ask follow-up questions, that could explore the topic further. From the open-end conversations new themes did arrive.

In total, seven people were interviewed in the care centre on the same day. The age of the participants ranged from 68 to 98 . Due to issues of mobility and the centre's resource capacity, it was not possible to interview participants in isolation from other service users at the centre. Interviewee's varied in their receptiveness to the questions. For example, some participants wanted a short interview (seven minutes), whereas some wanted a longer interview (fifteen minutes) so they could reflect upon past examples to shape their responses. With every interview, I learned how to improve my approach to get the most out of the responses.

One of the major drives behind my decision to explore this topic is quite personal. I have family members who care for the elderly, both in professional and non-professional contexts. From their experiences of care, I have observed that there are many stereotypes about how the elderly perceive certain issues. As a group, 'the elderly' are often assumed as incapable of using information technology. Fundamentally, I argue that we should not want technology to be created or prescribed to elderly people that ignores what they think and care about as individuals. 
Some scholars cite a need to address how much the elderly cost the state as a justification for their research [6]. However, this project is more concerned with exploring elderly people's perceptions of IT rather than uncovering how IT can assist the state in improving cost-effectiveness.

\section{Investigation}

Two weeks before the interviews took place, the participants were provided with the question 'Are you averse to technology?'. This gave them time to reflect on the question and come to possible conclusions prior to the interview. Each face-to-face interview was audio-recorded and conducted in a relaxed and familiar environment.

After giving their informed consent, participants were interviewed individually. A core issue was that there are some people at the day centre that could have dementia or Parkinson's. This was taken into consideration and before the interviews, the issue was discussed with the staff, and they selected participants.

1. What technology do you frequently use?

2. Do you have any privacy concerns with technology?

a. If so, what concerns?

3. Is there any technology that you will not use?

a. If so, why?

4. What technology have you liked using?

5. What technology have you disliked using?

6. Have you ever had IT lessons before?

7. Would you like to have IT lessons?

8. What do you generally think about the progression of modern technology?

The data analysis is a thematic analysis, this takes themes and ideas from the interviews. The data analysis has a 'products' and 'services' section. The intention of this is to show what the participants define technology as. This is important because they may have different ways of thinking about technology. As an example, if I asked them to talk about a specific technology, the participant may not go outside the area of the investigation. For example, if I asked a participant to talk about tablets, they may talk about the tablets, but they may not discuss their interactions with other technology, or what they think overall about technology. 


\section{$3 \quad$ Findings}

The findings are listed in the order of the amount talked about. Not measured from the text, rather the emphasis participants put into explaining the topics. So, in order the findings are:

- Family Pressure

- Childhood

- Progression

- Apathy

- Aversion

The findings suggest that participants have a wide range of opinions and views around 'technology'. The findings, however, show some trends. The first trend is family pressure. For participant three and one, they both mentioned that they were pressured by family to get a tablet or smartphone. For example, participant three stated that there was a long struggle with their family to get a smartphone, but even when participant three got a smartphone, they weren't entirely happy with it. Participant one mentioned that her family berated her until she got a tablet. Interestingly we need to see 'why' the family pressured or encouraged the participants to adopt a technology. In multiple cases the participants were using technology to contact family abroad, perhaps families believe that information technology enables communication. And perhaps as well, families are looking to buy presents for the participants and believed they were achieving giving a present and introducing a technology at the same time. Both points, however, need more direct research; something we will investigate later.

Three of the participants directly mentioned children. This is interesting because it doesn't directly affect themselves. Participant six mentioned childhood quite a lot. They stated that children are missing out on 'childhood' and children are growing up too fast. Three of the participants really had a concern for children and their use of technology. Participant three, when asked about technology progression, said: "It's over the top too much, especially for children, they don't know how to communicate properly."

The conversations included a comparison of experience between their childhood and the current childhood of the children they observe. For example, participant two sounded very nostalgic. Participant two stated that they cannot use technology because of their upbringing, physical photos, and further commented that people are 'zombified' and distracted. A key thing to take away from participant two is that they felt powerless to change society and their interactions with technology.

Like participant two, participant six mentioned progression and stated that they felt as though: 'Times have changed'. Perhaps this means that they feel like society is changing, and this is outside of their control. However, participant four and five accept that 'progression 'is happening and sound 
more optimistic about it. In fact, participant four stated that "it's going to make a lot of things better". Interestingly, the question "What do you generally think about the progression of modern technology?" doesn't define what progression is, what it involves and what technology.

Reflectively, this is great because it allows for the participants to express their emotions or express how they feel about something outside of a boundary setting. If the question was more specific perhaps the participant would have stated that they didn't know or care. For example, if I asked them if the progression of online shopping was a good thing, they may have given a specific answer. But, allowing for a general answer means that they don't have to be specific. When asked what they think about societal behaviour with technology, participant two said "They'll become zombies eventually, there is nothing you can change about it. It's at the hands of the people that create all this stuff. You cannot stop progression, people will stop using their heads." One quote that sticks out is: 'Times have changed, they say it's for the better, but I sometimes think is it for the better?'

Participant one and participant five when asked some questions answered "I don't know what I think about it' and 'I don't know, I just think it's a good thing'. Perhaps, they are either apathetic to answering questions and are not interested in the interview. However, considering the participants were told about the interview topic beforehand, perhaps these apathetic answers are more telling. Perhaps the participants do not care about technology, they may not think of it or are not interested. For example, participant five further mentioned that 'There's no one I want to phone, all my friends are here'.

This research shows how vague aversion is, and how hard it is to define it. Many of the participants said that they felt as if they didn't like technology, by their own definition. However, many participants were using technology around them. Many participants were using smartphones to phone people across the world, voice call those around, pay bills online or play board games on mobile devices. The participants can use a technology and still dislike it. It is possible that the participants see it as means to an end, a necessity to communicate, play games or search things online. You could assume that if asked 'Do you like communicating?', 'Do you like playing Scrabble?' or 'Do you like searching things online?' The participants may answer that they do, perhaps a lot of people would answer that they like communicating.

So, the devices may seem like a necessity to do these things, but this does not suggest that they like the devices they have. For example, participant six stated that technology 'drives them mad', but they further explained that it was a necessity to speak to their daughter in Australia. In this case, participant six may value speaking to their daughter enough to use the technology that they acclaimed 'drive them mad'. From this, it is urged that anyone analysing elderly interactions with technology recognise that just because an elderly person uses a technology, doesn't mean that they like it. In participant six's case, they could hate it, but find it useful. This questions 
what it means to say that you 'like' or 'dislike' something, which will further be explored in the discussion.

Perhaps the participants do not have an interest in technology but find the use of technology necessary. For example, in Heart et al. research $62 \%$ of the participants, when asked why they don't use computers stated that they have 'no need' or 'not interested' [6] . This questions what aversion really is, which is discussed further. From this, we can assume that we don't have to expect a person to have an opinion. In this case, at least, some participants simply did not care for technology and didn't care to involve themselves.

\section{$4 \quad$ Discussion}

Bednar states that a system is defined by interest [2] These findings support Bednar statements because systemically, the elderly have different interests in technology. For example, in this case some of the elderly participants see technology as a means of communication. Further, some of the elderly participants are interested in using technology for games. So, these different interests define the purpose of 'technology'.

Family pressure was the strongest theme. As found in the research, perhaps the reason for this family pressure is the want or need for communication. For example, many participants mentioned that they wanted a technology, so they could speak to family abroad or to distant new grandchildren. The participants mentioned distance, and the use of this technology as a tool to virtually shorten it. Research has found in between 1970 to 2000 in Europe that the propensity of an elderly person living alone had increased [17]. In Great Britain about one-half of the elderly participants in Tomassini et al. research stated that they are in contact with their children at least once a week. [17] Albeit in 2004, this research suggests that half of the elderly people in Great Britain are not in contact with their children on a weekly basis. Tomassini et al. indicate that frequency of contact can strengthen potential support for elderly people [17]. Perhaps, therefore, family members feel a need to pressure their parents or grandparents into adopting aspects of technology, to communicate and support them.

Interesting though, this family pressure has been mentioned by Asghar et al [1] and Vacek et al [19] They suggest that there may be a correlation between social inclusion and technology use. These studies found that where an elderly person is socially excluded they are less likely to be taught a technology or be introduced to that technology. Perhaps, the family pressure isn't necessarily a negative thing, but just an element of social inclusion.

With a boundary setting bigger than just the participant and a technology we found the complexity of the external world. The research found, in many 
cases, that a participant wasn't always concerned about themselves, but they were concerned with the external, in this case, children. Within the research, we asked whether the elderly are averse to technology and assumed that if they are, it is because of things affecting them. This includes; privacy concerns, lack of education, usability, and security. Never did we wonder whether an elderly person was concerned about technology that did not directly affect them, for example, children or society. There needs to be further research on this topic.

Again, in the research design, there was no mention of concern for society, something that doesn't directly involve a participant. Some participants stated that technological and societal progression was a good thing, but most didn't. We can take from this, that not only do some participants think that society progression is good, or some think that it is bad, but that they all think it is moving or happening. Many mentioned that it was out of their control, and that time would tell. To summarise, perhaps you can be averse to something that does not directly affect you.

Contrary to the secondary research, within the primary research participants didn't have many complaints about usability. In fact, one participant mentioned that usability was an issue in the past, but not now. Cooper, a critic of poorly designed technology suggested that the technology industry was causing a software apartheid [3]. However, this research was in 2004 and this papers research was in 2018. This could suggest that usability design has improved, specifically with mobile phones and tablets. Ashgar et al research found that most of their participants felt comfortable with using 'assistive technology' [1] This could suggest that there has been a change in usability design between those years.

In the research, we questioned what aversion is. In addition, we questioned what it meant to feel averse to something. For example, many of the participants said that they liked playing scrabble on their tablets. If we based the research on tablets and if they said they enjoy playing games on it, we may have concluded that the participants like playing scrabble on tablets. in This context, it is purposeless. We wanted to find out how they 'felt' about something not if they use something,

The technology must have a purposeful action, for example phone calls or playing games. Contextually as mentioned earlier, a participant's interactions with technology is characterised by purposeful action and they will interpret technology in different ways, as they interpret the world in different ways [4]. As we have learnt the participants do interpret the world in different ways, and when we allowed for complexity in the open-ended conversations we found a wide interpretation of the world.

Even though Skyme et al and Heart et al questioned the opinions of their participants directly, other research has segmented technology use. Just because an elderly person has security concerns regarding a technology, does not mean that they dislike technology. Just because an elderly person finds 
some technology to be unusable, it does not mean that they dislike technology. In addition, just because they communicate with their family without the restraints of geographic location, does not mean that they like technology. Therefore, we need to question what it is to be averse.

From this discussion, there must be further research. We can gather that the elderly perceive technology as not just internal, but external. This is to suggest that that the elderly care about how technology affects others, not necessarily themselves. In a society where many may be using a technology we may propagate a digital divide.

\section{Conclusion}

To conclude, the answer to the question "Are the elderly averse to technology?" is that the elderly includes a wide range of people, they have many different opinions and beliefs, and from the research, there are themes and trends that arrive. These themes are trends include the family pressure, children, apathy, usability, and their past interactions.

Before anything else, there needs to be more research into the family pressures that pressure the elderly into using technology. Hopefully, this research may find a mix of pressures, hidden pressure, and wrongly assumed pressure. This research would be important to find the pressures that elderly people have, and the influence of technology.

Furthermore, there needs to be more research into what the elderly think about their external world. As mentioned throughout this project, elderly people talk a lot about the external world, perhaps more than their internal world. It would be interesting to research what they care about, external to them. For example, the project found that some participants have a big concern for the impact of technology on children, and not so much themselves.

\section{References}

1. Asgha, I., Shuang, C., Hongnian, Y.: Usability evaluation of assistive technologies through qualitative research focusing on people with mild dementia. Computers in Human Behaviour, 79, 192-201 (2018)

2. Bednar, P.: Socio-Technical Toolbox for Business Analysis in Practice. In Caporaello, L., Di Martino, B., \& Martinez, M. (Eds.). Smart Organizations and Smart Artifacts. Springer (2014)

3. Cooper, A.: The Inmates are running the asylum, why high-tech products drive us crazy and how to restore the sanity. $2^{\text {nd }}$ Edition. Sams. (2004)

4. Checkland, P., Scholes, J.: Soft Systems Methodology in Action. Chichester: John Wiley \& Sons Ltd (1990)

5. Hanson, M.: Older people can't cope with new technology - but nobody cares. The Guardian. (2017, 3 April).

6. Heart, T., Kalderon, E: Older adults: Are they ready to adopt health-related ICT?

International Journal of Medical Informatics, 82(11), 209-231 (2013). 
7. Iwasaki, N.: Usability of ICT applications for elderly people in disaster reduction. Journal of E-Governance, 36(2), 73-78 (2013)

8. Kirchbuchner, F., Grosse-Puppendahl, T., Hastall, M. R., Distler, M., Kuijper, A.: Ambient intelligence from senior citizens' perspectives: Understanding privacy concerns, technology acceptance, and expectations. European Conference on Ambient Intelligence, 48-59. (2014).

9. Leroi, I., Robert, P.: Apathy in the Elderly: From Assessment to Treatment. Current Gerontology and Geriatrics Research, 1-2. (2012).

10. Martin, C. A., Tulgan, B.: Managing the Generation Mix. Amherst: HRD PRESS, INC. (2006)

11. Marzano, G., Lubinka, V.: Usability in social telerehabilitation systems for elderly users. Public Health, 144, 1-3. (2014)

12. McIntosh-Elkins, J., McRitchie, K., Scoones, M. Strategies for Managing the Generation Mix. From the Silent Generation to Generation X, Y and Z, 240-246. (2007).

13. Mumford, E.: Designing Human Systems for New Technology: The Ethics Method. Manchester: Manchester Business School (2013)

14. Padilla-Góngora, D., López-Liria, R., Díaz-López, M. d., Aguilar-Parra, J. M., VargasMuñoz, M. E., Rocamora-Pérez, P.: Habits of the Elderly regarding Access to the New Information and Communication Technologies. Procedia - Social and Behavioral Sciences, 237, 1412-1417. (2017).

15. Skymne, C., Dahlin-Ivanoff, S., Claesoon, L., Eklund, K.: Getting used to assistive devices: Ambivalent experiences by frail elderly persons. Scandinavian Journal of Occupational Therapy, 19(2), 194-203 (2012).

16. Stowell, F. The Manager's Guide to systems Practice. Chichester: John Wiley \& Sons Ltd (2012).

17.Tomassini, C., Kalagirou, S., Grundy, E., Fokkema, T., Martikainen, P., Broese van Groenou, M., \& Karisto, A.: Contacts between elderly parents and their children in four European countries: current patterns and future prospects. Eur J Ageing, 1(1), 54-63. (2004)

18. Troksa, L. M.: The Study of Generations: A Timeless Notion within a Contemporary Context. Colorado: University of Colorado. (2016).

19. Vacek, P., Rybenska, K.: Research of Interest in ICT education among seniors. Procedia Social and Behavioral Sciences 171, 171(16), 1038-1045. (2015).

20. Venkatesh, V., David, F. D.: A Model of the Antecedents of Perceived Ease of Use: Development And Test. Decision Sciences, 27(3), 451-481. (1996).

21. Wahab, S. A., Rose, R. C., Osman, S. I.: A Literature Analysis. Defining the Concepts of Technology and Technology Transfer, 61-71. (2012).

22.Yusif, S., Soar, J., \& Hafezz-Baid, A.: Older people, assistive technologies, and the barriers to adoption: A systematic review. International Journal of Medical Informatics, 112(6), 112-116. (2016). 